\title{
SCIENTIFIC REPORTS

\section{OPEN Computed Tomography-based evaluation of porcine cardiac dimensions to assist in pre-study planning and optimized model selection for pre-clinical research}

\begin{abstract}
Miriam Lipiski ${ }^{1^{*}}$, Matthias Eberhard ${ }^{2}$, Thea Fleischmann ${ }^{1}$, Sascha Halvachizadeh ${ }^{3}$, Beate Kolb ${ }^{2}$, Francesco Maisano ${ }^{4}$, Mareike Sauer ${ }^{1}$, Volkmar Falk ${ }^{5,6,7}$, Maximilian Y. Emmert ${ }^{5,6}$, Hatem Alkadhi ${ }^{2}$ \& Nikola Cesarovic ${ }^{1,7}$

The pig (Sus Scrofa Domestica) is an accepted model for preclinical evaluation of prosthetic heart valves and trans-catheter implantation techniques. Understanding porcine cardiac dimensions through threedimensional computed tomography (CT), increases preclinical study success, leading to higher cost efficiency and to the observance of the obligation to the $3 \mathrm{R}$ principles. Cardiac CT images of twentyfour Swiss large white pigs were segmented; aortic root, mitral valve, pulmonary trunk, tricuspid valve, as well as the aorto-mitral angle and left atrial height were analyzed. Correlation coefficient ( $r$ ) was calculated in relation to body weight. In Swiss large white pigs, valvular dimensions, length of the pulmonary artery and ascending aorta as well as left atrial height correlate with body weight. Coronary ostia heights and aorto-mitral angle size can be neglected in animal size selection; no changes were found for either of the two parameters with increasing body weight.
\end{abstract}

Driven by advancing technologies and skills, cardiology and cardiac surgery had been one of the medical fields quick to embrace minimally invasive techniques such as trans-catheter valve therapies in the early $2000 \mathrm{~s}^{1,2}$. Minimally invasive techniques are generally accompanied by an improved patient satisfaction, a higher return to normality, a lesser requirement for post-rehabilitation services, and a marked reduction of costs ${ }^{3}$. Trans-catheter approaches have now been fully integrated into the therapeutic portfolio for managing patients suffering from cardiac disease with a risk too high for conventional surgery ${ }^{4}$, thus, leading to a high demand in development of new trans-catheter devices and new types of delivery systems ${ }^{5}$.

The use of large animal models in pre-clinical studies plays an important role in the initial evaluation of efficacy and safety of new medical devices before their use in human clinical trials ${ }^{6-8}$. The domestic pig (Sus Scrofa Domestica) is a widely accepted animal model of cardiovascular research and in particular for the preclinical evaluation of prosthetic heart valves and trans-catheter implantation techniques ${ }^{9}$. However, trans-catheter valve implantations in pigs, are often associated with the same complications as seen in humans, namely post-implantation para-valvular regurgitation, coronary occlusion and rupture of the aortic root or annulus due to oversizing of the valve ${ }^{10,11}$. Furthermore, left atrial volume and dimensions can be smaller in pigs for equivalent annulus size seen in humans ${ }^{12}$, therefore high profile valves in pigs may lead to obstruction or reduction of the pulmonary vein inflow and in case of touching the left atrial roof causing complications such as tissue erosion or cardiac arrhythmias ${ }^{13}$. High profile valves may also cause obstruction of the left ventricular outflow tract due to the geometric relationship between the aortic and the mitral valve ${ }^{13}$. Pre-procedural planning with modern

${ }^{1}$ Division of Surgical Research, University Hospital Zurich, University of Zurich, Zurich, Switzerland. ${ }^{2}$ Institute for Diagnostic and Interventional Radiology, University Hospital Zurich, Zurich, Switzerland. ${ }^{3}$ Department of Trauma, University Hospital Zurich, Zurich, Switzerland. ${ }^{4}$ Department of Cardiac Surgery, University Heart Center Zurich, Zurich, Switzerland. ${ }^{5}$ Department of Cardiovascular Surgery, Charité Universitätsmedizin Berlin, Berlin, Germany. ${ }^{6}$ Department of Cardiothoracic and Vascular Surgery, German Heart Institute Berlin, Berlin, Germany. ${ }^{7}$ Department of Health Sciences and Technology, ETH Zurich, Zurich, Switzerland. *email: Miriam.Lipiski@usz.ch 
imaging modalities such as trans-esophageal echocardiography and three-dimensional computed tomography (CT) have shown to lead to a better understanding of annular sizing and geometry and a reduction of these complications and have therefore become an integral part in the clinical assessment of patients ${ }^{10,14-16}$.

Unlike in the human patient, where the valve is chosen based on the patient's annular size and geometry, in preclinical research a suitable animal is generally selected based on body weight for one particular valve size available for testing. Thus, the suitable animal must be large enough to accommodate human-grade devices, with the determining factors being the size of the target cardiac structure, as well as the diameter of the peripheral vessels used for vascular access ${ }^{17}$.

Studies in humans described a strong correlation between body surface area to normal aortic and pulmonary valve diameter. Other strong predictors of valve diameter include the patient's age and body height ${ }^{18}$. Body weight and Body Mass Index (BMI) on the other hand are rather poor indicators of valve size in humans ${ }^{18}$. As for the pig, Allan et al. could also find a positive correlation between the body length and the aortic annulus and root diameter in the miniature swine ${ }^{19}$. Although miniature swine have become increasingly popular in research, the purchase price is markedly higher than for commercially raised farm breeds, which makes the latter more popular for acute and short term studies ${ }^{20}$. Additionally, most of miniature swine breeds will not reach the heart and blood vessel size which most closely approximates that of humans, precluding them from testing human-size implants ${ }^{21}$.

Implementing CT as an integral part of animal selection would be ideal however, although non-invasive imaging procedures are of low severity grade based on the severity classification of the EU Directive $2010 / 63^{22}$, they do require adequate sedation or general anesthesia and therefore an additional authorization from the competent authorities.

Therefore, in this study, cardiac CT images of commercial farm pigs of the same breed but with different body weights were used to perform morphometric analyses of porcine cardiac structures. The goal was to assess correlation between the pig's body weight and the (intra) cardiac dimensions with the ultimate goal to allow for an accurate prediction of which animal would be the best weight-matched to test a particular size of cardiac implant. Thus, leading to an improved animal selection and enhanced preclinical study success.

\section{Methods}

Animal Study. Twenty-four domestic pigs (Swiss large white, intact females and castrated males) that had undergone pre-operative cardiac CT for a variety of different projects approved by the local Committee for Experimental Animal Research (Cantonal Veterinary Office Zurich, Switzerland) under the License numbers $152 / 2013,219 / 2016$ and 138/2017 were included into this study. Animal housing and all experimental procedures were in accordance with Swiss animal welfare protection law, and conform to European Directive 2010/63/EU of the European Parliament and the Council on the Protection of Animals used for Scientific Purposes, and to the Guide for the Care and Use of Laboratory Animals ${ }^{23}$.

Images were selected randomly and animals assigned to one of the following weight groups: $50-60 \mathrm{~kg}(\mathrm{n}=8)$, $80-90 \mathrm{~kg}(\mathrm{n}=8), 100-110(\mathrm{n}=8)$.

Animal Preparation. All pigs were sedated with an intramuscular injection of ketamine $\left(\operatorname{Ketasol}^{\circledR}-100\right.$ ad us.vet.; Dr. E. Graeub AG, Berne, Switzerland; $15 \mathrm{mg} / \mathrm{kg}$ body weight), azaperone (Stresnil ${ }^{\circledR}$ ad us.vet.; Elanco Tiergesundheit AG, Basel, Switzerland; $2 \mathrm{mg} / \mathrm{kg}$ body weight) and atropine (Atropinsulfat KA vet $0.1 \%$; Kantonsapotheke, Switzerland; $0.05 \mathrm{mg} / \mathrm{kg}$ body weight). Anesthesia was induced by an intravenous administration of propofol (Propofol ${ }^{\circledR}$ - Lipuro 1\%, B. Braun Medical AG; Sempach, Switzerland; 1-2 mg/kg body weight) to achieve relaxation and swallow-reflex diminishment sufficient for intubation. Anesthesia was maintained during the duration of the study with propofol $\left(5-10 \mathrm{mg} / \mathrm{kg} / \mathrm{h}\right.$ ). For pain medication buprenorphine (Temgesic ${ }^{\circledR}$; Indivior Schweiz AG, Baar, Switzerland; $0.01 \mathrm{mg} / \mathrm{kg}$ ) was administered.

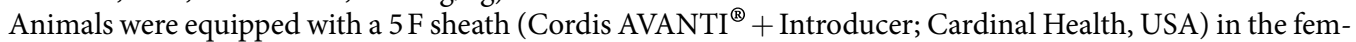
oral vein or an $18 \mathrm{G}$ auricular vein catheter (B. Braun Medical AG; Sempach, Switzerland) for contrast agent injection.

CT imaging protocol and data reconstruction. Animals were scanned under general anesthesia with a third-generation 192-slice dual-source CT machine (SOMATOM Definition Flash, Siemens Healthineers, Forchheim, Germany). The data acquisition was synchronized with the electrocardiogram (ECG) of the animals using retrospective ECG-gating and using the following scan parameters: detector collimation $2 \times 0.6 \times 96$, slice acquisition $2 \times 0.6 \times 192$ by means of a $\mathrm{z}$-flying focal spot, gantry rotation time $0.25 \mathrm{~s}$, tube current-time product $380 \mathrm{mAs} /$ rotation, and tube voltage $120 \mathrm{kVp}$. A total of $0.5-1 \mathrm{ml} / \mathrm{kg} \mathrm{BW}$ iodinated contrast media (iopromide, Ultravist 370, Bayer Healthcare, Berlin, Germany) was administered intravenously at a flow-rate of $5 \mathrm{ml} / \mathrm{s}$ followed by $30 \mathrm{ml}$ of saline chaser at a flow-rate of $3.5 \mathrm{ml} / \mathrm{s}$.. Bolus tracking was performed in the ascending aorta. The contrast-enhanced CT scan was initiated after an attenuation threshold of 120 Hounsfield units [HU] at $100 \mathrm{kV}$ was reached. Mean attenuation of the ascending aorta, left ventricle and right ventricle was $375 \pm 130 \mathrm{HU}$, $368 \pm 124 \mathrm{HU}$, and $367 \pm 156 \mathrm{HU}$, respectively.

All CT data was reconstructed using a slice thickness of $0.6 \mathrm{~mm}$ and increment of $0.4 \mathrm{~mm}$ using advanced modeled iterative reconstructions (ADMIRE) at a strength level of 4 . The reconstruction field-of-view (FoV) was set to $200 \mathrm{~mm}$ with a pixel matrix of $512 \times 512$. Images were reconstructed in $10 \%$ steps of the RR-interval.

Data Analysis. All measurements were performed using 3mensio structural heart software Version 9.1 (3mensio Medical Imaging BV; Bilthoven; the Netherlands) (Figs. 1 and 2).

Aortic Root. Aortic root measurements were performed in diastole, following manual segmentation of the ascending aorta. The following measurements were acquired: diameter by area derived and perimeter derived 

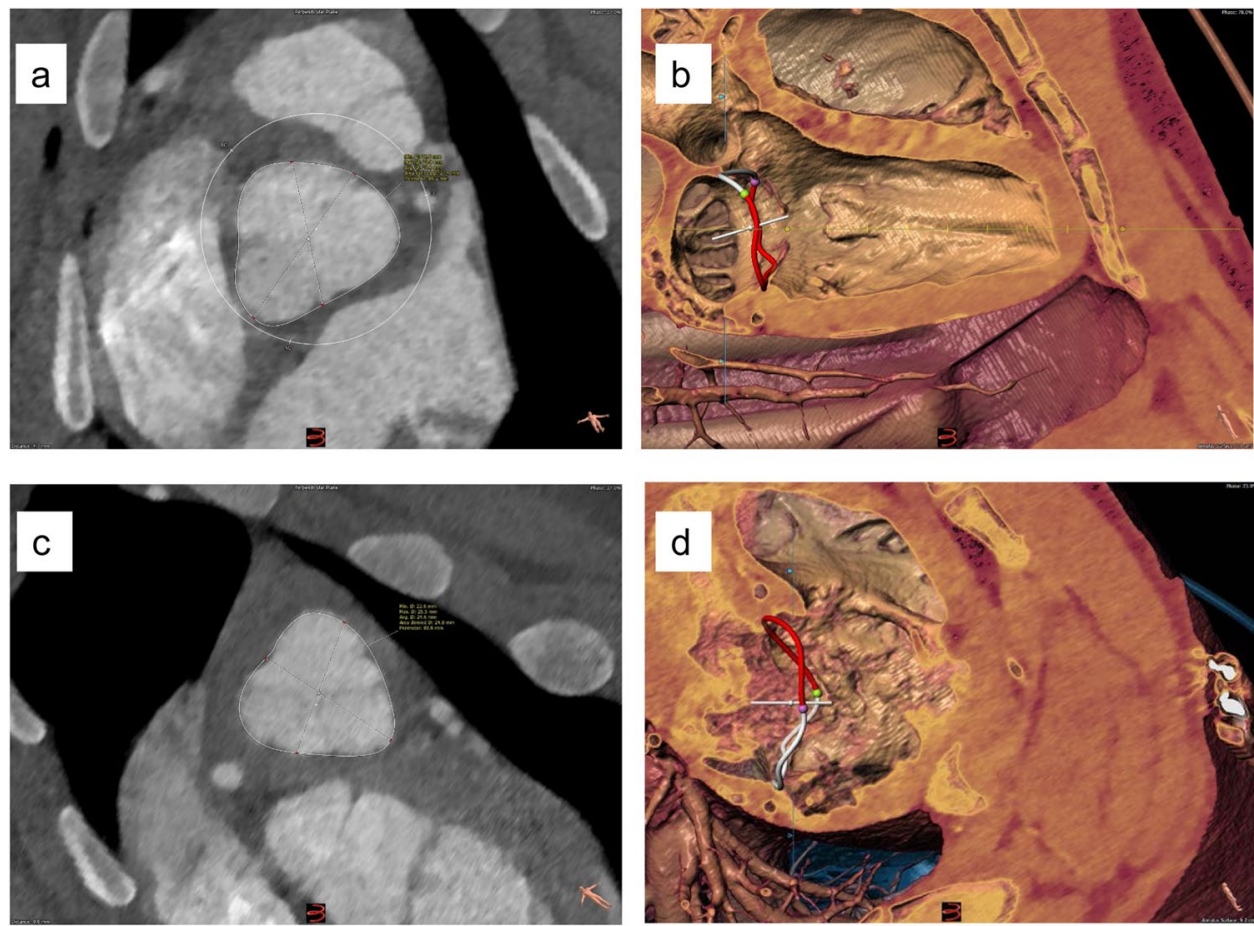

Figure 1. Representative Segmentation examples: Aortic Valve (a), Mitral Valve (b), Pulmonary Valve (c) and Tricuspid Valve (d).
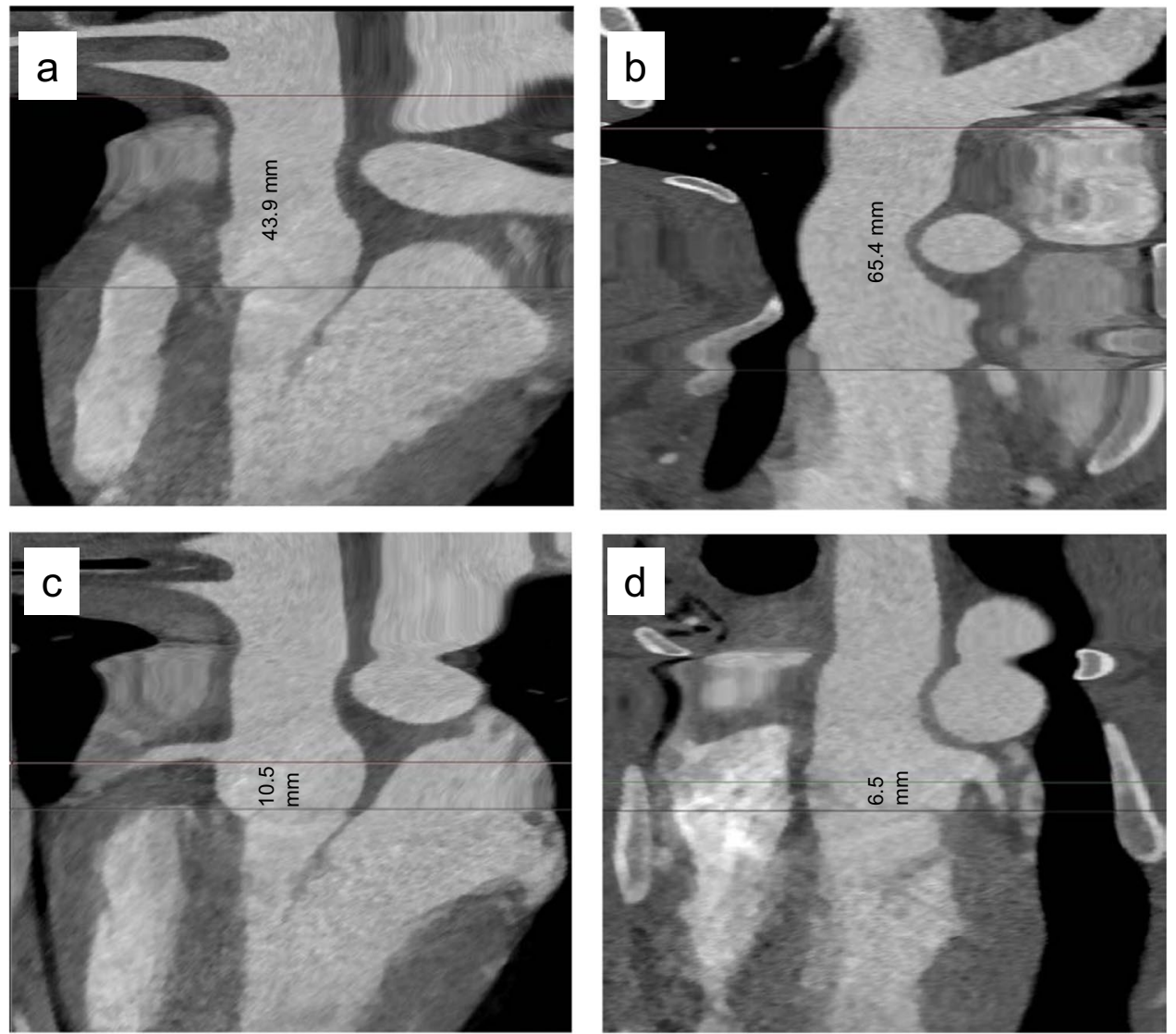

Figure 2. Representative Segmentation example: Length of ascending aorta (a), length of pulmonary trunk to bifurcation (b), RCA Ostium height (c) and LCA Ostium height (d). 
annulus size; size of the left ventricular outflow tract (LVOT; $5 \mathrm{~mm}$ below the annulus plane). Length measurements were performed on the stretched vessel view, namely, length from annulus to the left coronary artery (LCA) ostia and the right coronary artery (RCA) ostia; length of the ascending aorta from annulus to the branch-off of the brachiocephalic trunk.

Mitral Valve. The following annulus dimensions were acquired in systole: Area; perimeter - in particular posterior perimeter, trigone-to-trigone (T-T) distance, septo-lateral (S-L) and commissure-to-commissure (C-C) distance.

Aortic-Mitral Angle. Aortic-Mitral Angle was measured in systole.

Pulmonary Trunk. Pulmonary trunk measurements were performed in diastole, following manual segmentation of the pulmonary artery. The following measurements were acquired: diameter by area derived and perimeter derived pulmonary annulus size; area and diameter of the pulmonary artery $(20 \mathrm{~mm}$ above the annulus plane). Length measurements were performed on the stretched vessel view, namely, length from annulus to the bifurcation.

Tricuspid Valve. The following annulus dimensions were acquired in systole: area, perimeter, septo-lateral (S-L) distance, maximum diameter.

Left atrial height. left atrial height was measured in both systole and diastole.

Statistical analyses. All analyses were performed with GraphPad Prism software version 8.0.0. Correlation coefficients ( $r$ ) were computed using Spearman nonparametric correlation. Strength of association was defined as very weak correlation (positive and negative 0.01 to 0.19 ), weak correlation (positive and negative 0.20 to 0.39 ), moderate correlation (positive and negative 0.40 to 0.69 ), strong correlation (positive and negative 0.70 to 0.89 ) and very strong correlation (positive and negative 0.90 to 1.00). A two-tailed P value was computed, significance for all statistical tests was established at $\mathrm{p} \leq 0.05$. Correlation was determined between each column versus body weight. Columns assed were: all measurements acquired under aortic root, pulmonary trunk, mitral valve, tricuspid valve and left atrial height.

Additionally, a correlation matrix was created between all valve area sizes, LCA and RCA ostia height, coronary heights and length of ascending aorta.

\section{Results}

Aortic Root. A strong correlation was found between body weight and aortic valve diameter $(r=0.83$, $\mathrm{p}<0.0001)$ and aortic valve area, respectively $(\mathrm{r}=0.84, \mathrm{p}<0.0001)$, as well as between body weight and length of the ascending aorta $(\mathrm{r}=0.72, \mathrm{p}<0.0001)$ (Fig. 3). A moderate correlation was found between the body weight and LVOT diameter $(\mathrm{r}=0.64, \mathrm{p}=0.0007)$. Correlation between body weight and LCA ostium was not significant $(\mathrm{r}=0.32, \mathrm{p}=0.123)$, while the same correlation with the RCA ostium height was moderate $(\mathrm{r}=0.52, \mathrm{p}=0.0095)$. Correlation between RCA ostium height and length of ascending aorta $(r=0.38, p=0.066 ; r=0.32)$ was not significant, similar to the correlation between LCA ostium height and length of the ascending aorta $(r=0.07$, $\mathrm{p}=0.757)$. Correlation between RCA and LCA ostia height was found to be moderate $(\mathrm{r}=0.50, \mathrm{p}=0.014)$.

Aortic-Mitral Angle. There was no significant correlation between body weight and aortic-mitral angle $(\mathrm{r}=0.09, \mathrm{p}=0.66)$.

Mitral Valve. A strong correlation was found between body weight and T-T distance $(\mathrm{r}=0.73, \mathrm{p}<0.0001)$ as well as between body weight and left atrial height $(r=0.76, p<0.0001)$ (Fig. 4). Correlations between body weight and mitral valve area, body weight and $\mathrm{C}-\mathrm{C}$ distance, body weight and $\mathrm{S}$ - $\mathrm{L}$ distance as well as body weight to posterior perimeter was moderate $(\mathrm{r}=0.56, \mathrm{p}=0.0037 ; \mathrm{r}=0.44, \mathrm{p}=0.0297 ; \mathrm{r}=0.49, \mathrm{p}=0.0143 ; \mathrm{r}=0.43$, $\mathrm{p}=0.0338)$.

Pulmonary Trunk. A strong correlation was found between body weight and length of the pulmonary artery to bifurcation $(\mathrm{r}=0.81, \mathrm{p}<0.0001)$ (Fig. 5). Correlations between body weight and pulmonary artery diameter $(\mathrm{r}=0.55, \mathrm{p}=0.0059)$, pulmonary valve diameter $(\mathrm{r}=0.61, \mathrm{p}=0.0019)$, and pulmonary valve area $(\mathrm{r}=0.56$, $\mathrm{p}=0.0054)$ were moderate.

Tricuspid Valve. A moderate correlation was found between body weight and maximum tricuspid valve diameter $(r=0.46, p=0.027)$ (Fig. 6). There was no significant correlation between body weight and tricuspid valve area, and between body weight $\mathrm{S}-\mathrm{L}$ distance $(\mathrm{r}=0.19, \mathrm{p}=0.3913 ; \mathrm{r}=0.04, \mathrm{p}=0.8520)$.

Valve area sizes. Correlation matrix for all valve areas revealed the following correlations: A strong positive correlation was found between aortic valve area and mitral valve area $(r=0.70, p<0.0001)$, correlation between aortic valve area and pulmonary valve area was moderate $(\mathrm{r}=0.51, \mathrm{p}=0.014)$. A moderate correlation was also found between mitral valve area and tricuspid valve area $(\mathrm{r}=0.59, \mathrm{p}=0.004)$. No significant correlation was found between aortic valve area and tricuspid valve area $(\mathrm{r}=0.38, \mathrm{p}=0.081)$, between mitral valve area and pulmonary valve area $(r=0.15, p=0.498)$, and between tricuspid valve area and pulmonary valve area $(r=-0.12$, $\mathrm{p}=0.617)$. 
a
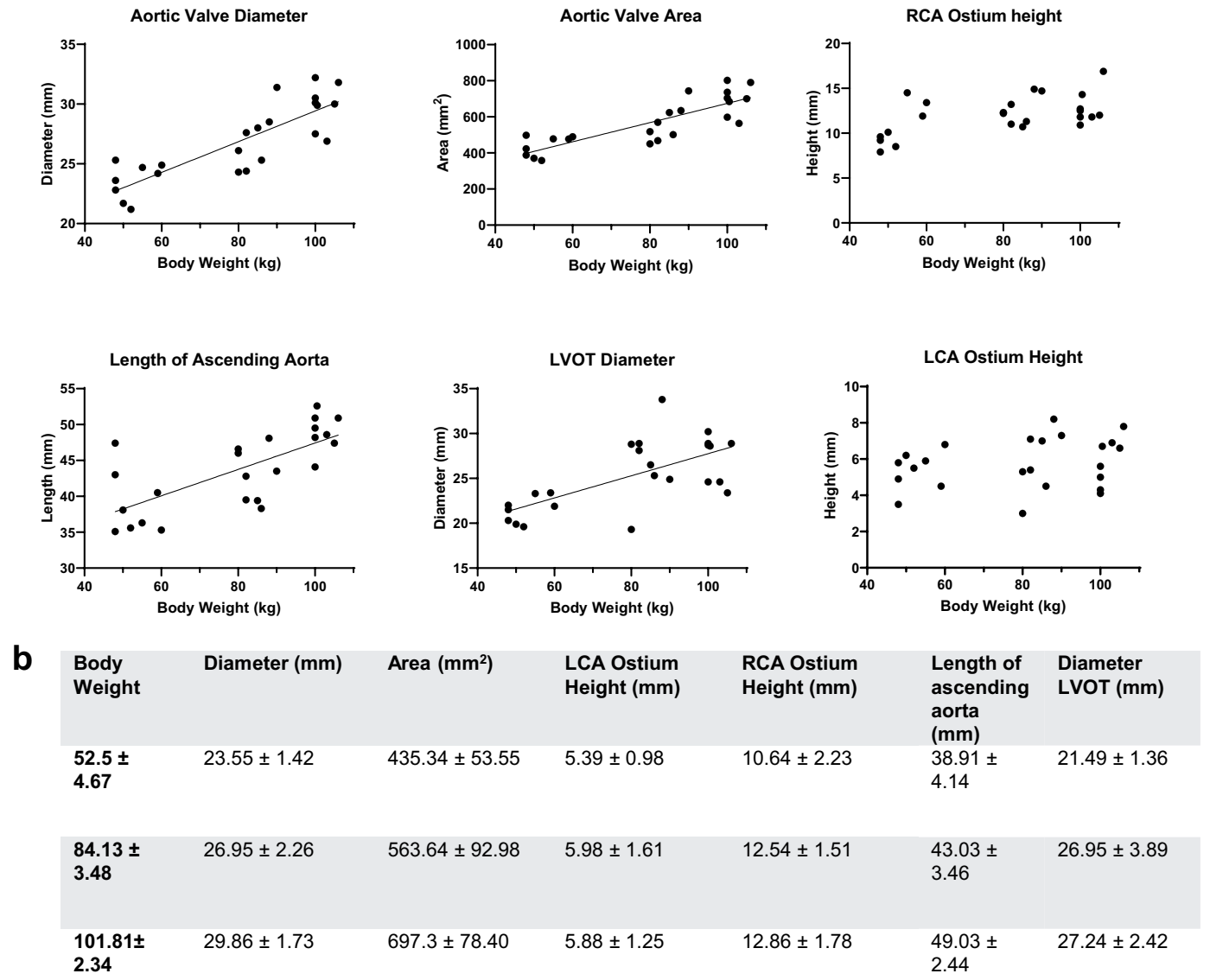

Figure 3. Aortic Root; a. Aortic Valve Diameter, Aortic Valve Area, RCA/LCA Ostium height, Length of Ascending Aorta, LVOT Diameter: Each parameter is correlated to body weight; each dot represents a single value. A linear regression line was fitted for parameters with moderate to strong correlation. (b) Values for the measured parameters are shown as Mean \pm SD; Values are grouped in three groups of different body weights $(50-60 \mathrm{~kg}(\mathrm{n}=8), 80-90 \mathrm{~kg}(\mathrm{n}=8), 100-110(\mathrm{n}=8))$.

\section{Discussion}

Heart valve prosthesis are designated as high-risk medical devices, requiring rigorous in-vitro and in-vivo safety, efficacy and/or performance studies ${ }^{24}$. The use of standardized animal models for preclinical testing is thereby essential to provide invaluable information on the device safety. Choosing a suitable animal model for a particular experiment is of great importance and can significantly affect the outcome of a study ${ }^{25,26}$. Over the last decades, public concern about animal welfare in biomedical research has evolved markedly resulting in the $3 \mathrm{R}$ principles (i.e. replace, reduce, refine) being established worldwide as the ethical approach in regulating the use of animals for scientific purposes ${ }^{27}$. The aim of the refine-principle requires the use of improved experimental techniques particularly when testing new medical devices and biomaterials in animal models.

The pig has been widely used as a model in cardiovascular research ${ }^{9}$ with a broad acceptance in the literature that the anatomy of the pig's heart is nearly identical to that of man ${ }^{28-30}$. In fact, trans-catheter valve implantations in pigs used for pre-clinical studies are often associated with the same complications as seen in humans ${ }^{10,11}$. However, unlike in humans, complications in pigs are often a consequence of a size mismatch, as preclinical studies are mostly performed with prototype devices of limited size variations $\mathrm{s}^{31,32}$. While undersizing of prosthetic valves leads to para-valvular leakage and dislodgment of the prosthesis ${ }^{33}$ oversizing significantly impairs hemodynamic performance ${ }^{34}$. As both scenarios have a negative impact on the informative value of the preclinical study results, appropriate annular measurements and prosthesis sizing are considered critical. A better understanding of cardiac morphometries, including the inter-species differences and intra-species anatomical variabilities, is thereby essential to improve safety and efficacy in non-clinical device evaluation ${ }^{14-16}$ and to concurrently reduce the possibility of misleading and meaningless study results lacking transferability ${ }^{35}$.

Adequate pre-procedural planning with modern imaging modalities such as three-dimensional CT is successfully used in clinical patients to ensure appropriate prosthesis-patient size matching and should therefore also be used for the pre-selection of study animals. In previous publications, detailed analysis of porcine cardiac anatomy was mainly achieved by gross examination and dissection ${ }^{12,36}$. However, a study in human patients has shown, that measurements acquired by CT are significantly more precise than intraoperative direct measurements. In-situ measurements appear to be highly influenced by the unphysiological state the cardiac structures 
a

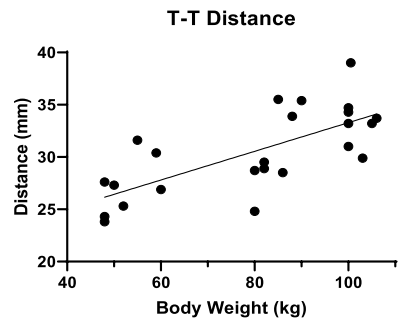

Mitral Valve Area

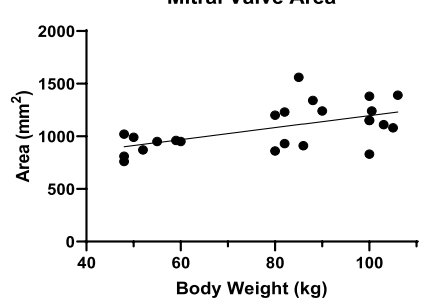

Left Atrial height

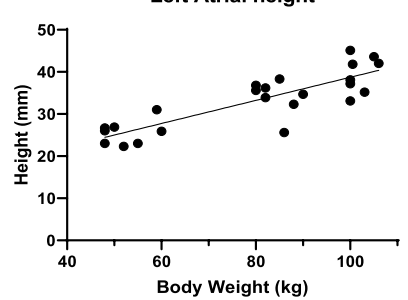

C-C Distance

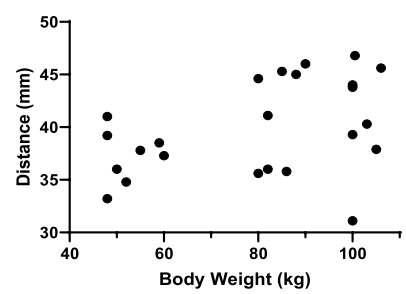

Posterior Perimeter

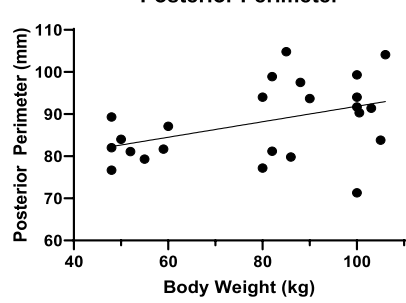

S-L Distance

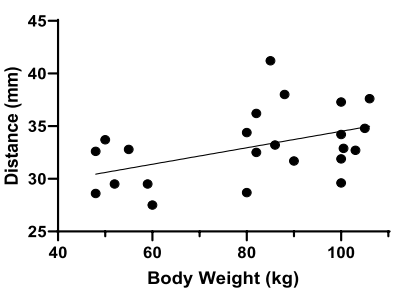

Aorto-Mitral Angle ( ${ }^{\circ}$ )

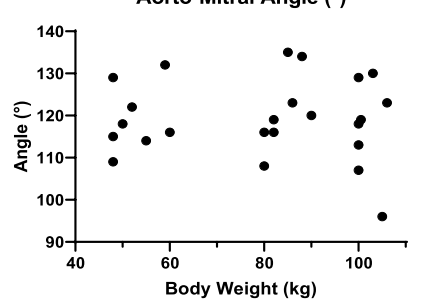

b

\begin{tabular}{|c|c|c|c|c|c|c|c|}
\hline $\begin{array}{l}\text { Body } \\
\text { Weight }\end{array}$ & $\mathrm{T}-\mathrm{T}(\mathrm{mm})$ & C-C $(\mathrm{mm})$ & S-L (mm) & Area $(\mathrm{mm} 2)$ & $\begin{array}{l}\text { Posterior } \\
\text { Perimeter } \\
(\mathrm{mm})\end{array}$ & $\begin{array}{l}\text { Aorto-Mitral } \\
\text { Angle }\left({ }^{\circ}\right)\end{array}$ & $\begin{array}{l}\text { Left Atrial } \\
\text { height }(\mathrm{mm})\end{array}$ \\
\hline $52.5 \pm 4.67$ & $27.15 \pm 2.58$ & $37.23 \pm 2.34$ & $30.36 \pm 2.17$ & $\begin{array}{l}913.75 \pm \\
85.28\end{array}$ & $\begin{array}{l}82.65 \pm \\
3.81\end{array}$ & $\begin{array}{l}119.38 \pm \\
7.31\end{array}$ & $\begin{array}{l}25.6 \pm \\
2.66\end{array}$ \\
\hline $84.13 \pm 3.48$ & $30.65 \pm 3.6$ & $41.18 \pm 4.38$ & $34.49 \pm 3.66$ & $\begin{array}{l}1158.75 \pm \\
226.57\end{array}$ & $\begin{array}{l}90.89 \pm \\
9.51\end{array}$ & $\begin{array}{l}121.38 \pm \\
8.60\end{array}$ & $\begin{array}{l}34.18 \pm \\
3.66\end{array}$ \\
\hline $\begin{array}{l}101.81 \pm \\
2.34\end{array}$ & $33.63 \pm 2.54$ & $41.1 \pm 4.78$ & $33.88 \pm 2.53$ & $\begin{array}{l}1166.25 \pm \\
167.85\end{array}$ & $\begin{array}{l}90.74 \pm \\
9.29\end{array}$ & $\begin{array}{l}116.88 \pm \\
10.67\end{array}$ & $\begin{array}{l}39.51 \pm \\
3.98\end{array}$ \\
\hline
\end{tabular}

Figure 4. Mitral Valve; a. T-T Distance, C-C Distance, S-L Distance, Mitral Valve Area, Posterior Perimeter, Aorto-Mitral Angle and Left Atrial Height: Each parameter is correlated to body weight; each dot represents a single value. A linear regression line was fitted for parameters with moderate to strong correlation. (b) Values for the measured parameters are shown as Mean $\pm \mathrm{SD}$; Values are grouped in three groups of different body weights $(50-60 \mathrm{~kg}(\mathrm{n}=8), 80-90 \mathrm{~kg}(\mathrm{n}=8), 100-110(\mathrm{n}=8))$.

are assessed in as well as numerous structural conditions including angle of the great heart vessels and compliance of the valvular annulus ${ }^{37}$.

Three-dimensional evaluation of coronary ostia height by CT is especially fundamental when planning transcatheter aortic valve implantation (TAVI). In human patients, ostia heights greater than $12 \mathrm{~mm}$ from the annulus are commonly considered safe for TAVI procedures ${ }^{38}$. This study however, not only showed the left coronary ostia to be markedly lower in pigs than in humans $(5.75 \pm 1.33 \mathrm{~mm}$ vs. $13.4 \pm 2.1 \mathrm{~mm})$, but no increase of coronary ostia height could be found with advanced body weight of the animals. Low coronary ostia are associated with a higher risk for post-implant coronary obstruction, depending on the type of implanted prosthesis, resulting in myocardial ischemia and infarction ${ }^{39}$. The question whether the lower coronary ostia height in pigs makes them unsuitable in the testing of TAVI procedures or enhances the development of novel TAVI strategies for intermediate-risk patients (coronary ostia height $<7 \mathrm{~mm}$ ), remains open.

Transcatheter mitral valve replacement (TMVR) is mainly challenged by high-profile delivery systems accommodating large valve prosthesis, having to overcome an extreme angle within a relatively small space, when approaching transseptally via the atrium to reach the mitral valve ${ }^{40}$. Left atrial height in pigs has shown to be strongly correlating with pig's body weight in this study. However, in pigs, the orientation of the heart along the cranio-caudal axes of the body resulting in a non-human cavo-apical angle poses an additional challenge on delivery devices ${ }^{41}$. Therefore, the transapical approach is a common alternative in TMVR procedures in pigs, making left ventricular dimension important factors to be considered in pre-surgical planning. Ventricular length 
a

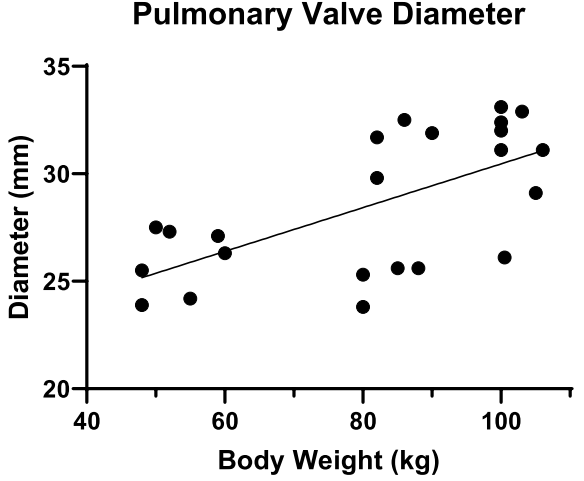

A. Pulmonalis Length

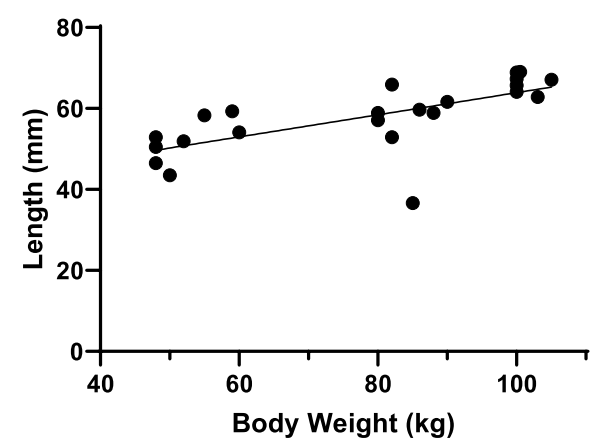

Pulmonary Valve Area

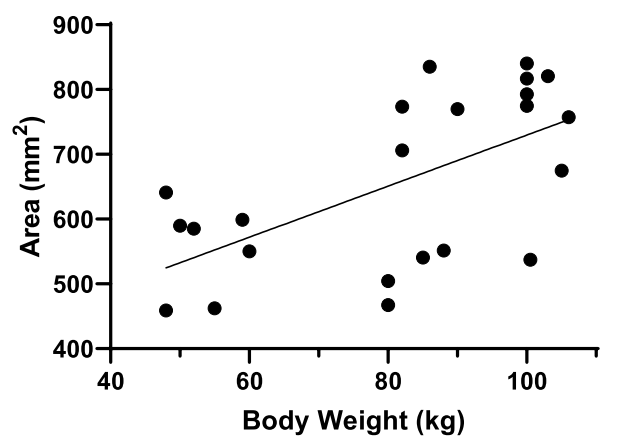

A. Pulmonalis Diameter

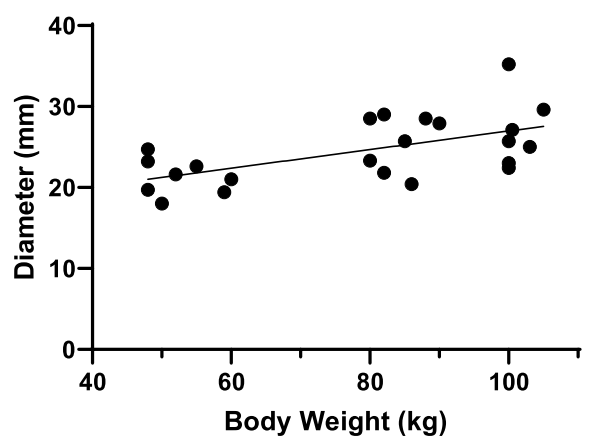

b

\begin{tabular}{|lllll}
\hline Body Weight & $\begin{array}{l}\text { Valve Diameter } \\
(\mathrm{mm})\end{array}$ & Valve Area $\left(\mathrm{mm}^{2}\right)$ & $\begin{array}{l}\text { Length to } \\
\text { Bifurcation }(\mathrm{mm})\end{array}$ & $\begin{array}{l}\text { A. Pulmonalis } \\
\text { Diameter }(\mathrm{mm})\end{array}$ \\
\hline $\mathbf{5 2 . 5} \pm \mathbf{4 . 6 7}$ & $25.97 \pm 1.37$ & $555.14 \pm 64.74$ & $52.13 \pm 5.04$ & $21.28 \pm 2.06$ \\
\hline $\mathbf{8 4 . 1 3} \pm \mathbf{3 . 4 8}$ & $28.28 \pm 3.32$ & $643.49 \pm 133.67$ & $56.45 \pm 8.28$ & $25.64 \pm 3.17$ \\
\hline $\mathbf{1 0 1 . 8 1 \pm 2 . 3 4}$ & $30.98 \pm 2.20$ & $751.76 \pm 94.22$ & $66.41 \pm 2.17$ & $26.86 \pm 4.08$ \\
\hline
\end{tabular}

Figure 5. Pulmonary Trunk; (a) Pulmonary Valve Diameter, Pulmonary Valve Area, A.Pulmonalis Diameter, Length of A. Pulmonalis: Each parameter is correlated to body weight; each dot represents a single value. A linear regression line was fitted for parameters with moderate to strong correlation. (b) Values for the measured parameters are shown as Mean $\pm \mathrm{SD}$; Values are grouped in three groups of different body weights (50-60 kg $(\mathrm{n}=8), 80-90 \mathrm{~kg}(\mathrm{n}=8), 100-110(\mathrm{n}=8))$.

shows no significant change with increased body weight in the animals included in this study (data not shown). Heart weight in modern farm pigs is thought to scale proportionally with body weight until the animals reach sexual maturity at the age of 4-5 months in males and 5-6 months in females ${ }^{42}$, corresponding to an approximate body weight of $80-90 \mathrm{~kg}$. The relative heart weight later decreases as the animals continue to grow ${ }^{36}$; leading to the assumption that measurements determining size of intra-cardiac structures reflect the above-mentioned flattening of the curve with increased body weight. Previous studies have shown a positive correlation between the body length and the aortic annulus and root diameter in the miniature swine ${ }^{19}$. In the presented study a positive correlation between body weight and aortic valve diameter, aortic valve area and the length of the ascending aorta could be confirmed in Swiss large white pigs. Furthermore, a strong positive correlation between body weight and the length of the pulmonary artery to bifurcation was observed. However, most of the intra-cardiac dimensions assessed in this study appear to fail in complying or only moderately comply with natural scaling laws.

A few hypothesis for this non-compliance can be proposed: Firstly, in commercially bred farm pigs the rate of fat deposition increases during the growth stages, leading to an inaccurate reflection of body weight ${ }^{43}$. Prediction equations for estimating lean body mass in farm pigs are available, however, they are not well established and were therefore not applied in the presented study ${ }^{44}$. Secondly, deviations in measurements due to selected cardiac phases. As the software used for analysis was unable to perform the automatic segmentation of the ascending aorta in pigs, all measurements of the aortic root were performed with the valve closed to facilitate accurate 
a

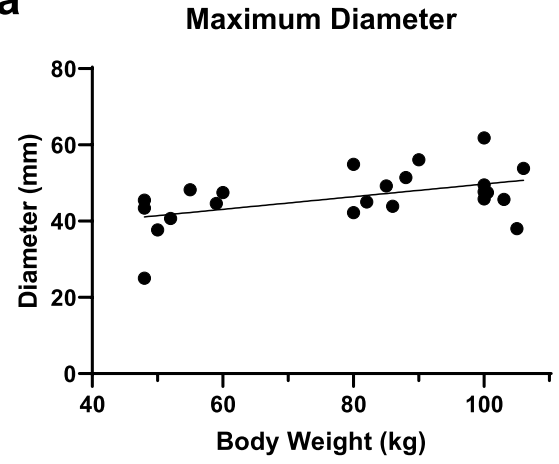

Tricuspid Valve Area

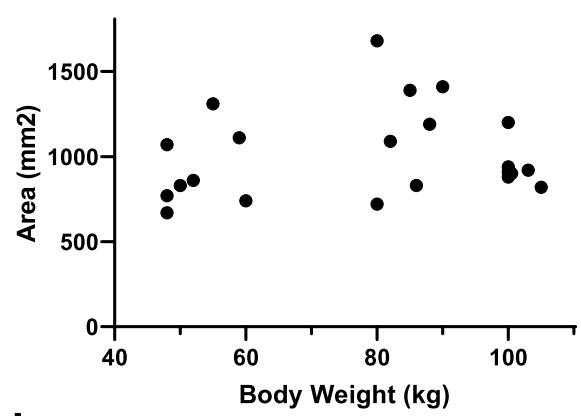

b

\begin{tabular}{llll}
$\begin{array}{l}\text { Body } \\
\text { Weight }\end{array}$ & $\begin{array}{l}\text { max. Diameter } \\
(\mathbf{m m})\end{array}$ & Area $\left(\mathbf{m m}^{2}\right)$ & S-L $(\mathbf{m m})$ \\
\hline $\mathbf{5 2 . 5} \pm$ & $41.58 \pm 7.09$ & $920 \pm 206.09$ & $24.58 \pm 5.04$ \\
$\mathbf{4 . 6 7}$ & & & \\
& & $1187.14 \pm$ & $31.31 \pm 6.10$ \\
$\mathbf{8 4 . 1 3} \pm$ & $48.96 \pm 5.06$ & 313.72 & \\
$\mathbf{3 . 4 8}$ & & & \\
& & $938.57 \pm$ & $23.89 \pm 3.63$ \\
\hline $\mathbf{1 0 1 . 8 1 \pm}$ & $48.76 \pm 6.45$ & 112.43 & \\
$\mathbf{2 . 3 4}$ & & &
\end{tabular}

S-L Distance

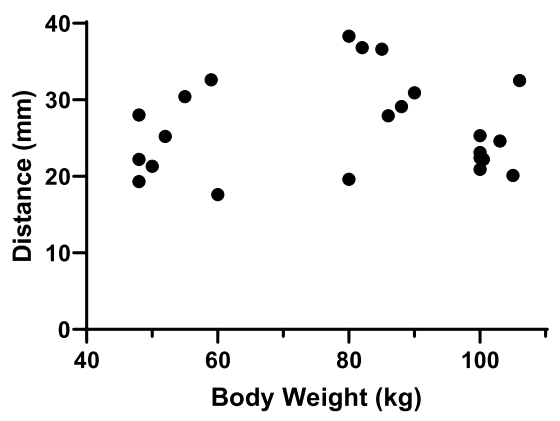

Figure 6. Tricuspid Valve; (a) Maximum Valve Diameter, S-L Distance, Tricuspid Valve Area: Each parameter is correlated to body weight; each dot represents a single value. A linear regression line was fitted for parameters with moderate to strong correlation. (b) Values for the measured parameters are shown as Mean \pm SD; Values are grouped in three groups of different body weights $(50-60 \mathrm{~kg}(\mathrm{n}=8), 80-90 \mathrm{~kg}(\mathrm{n}=8), 100-110(\mathrm{n}=8))$.

manual identification of the most basal attachment points of the three aortic valve cusps needed for quantitative assessment of the annulus plane $e^{45}$. All other valves were subsequently also measured in the closed position although intra-cardiac cycle variations are known to have a marked influence on cardiac dimensions and indices of cardiac functions in humans ${ }^{46}$ with differences of up to $15 \%$ expected when using different cardiac phases ${ }^{47}$. Best correlation has shown to be achieved when measurements are done in mid-systole in $25-35 \%$ of the heart cycle $^{48}$. Data on the amount of cyclical changes on annular dimensions in pigs, including cross-sectional area, perimeter and subsequently derived diameters however is more conflicting ${ }^{34}$. A dynamic geometry, mainly affecting the maximal diameter but not the minimal diameter, throughout the cardiac cycle is described for the left ventricular outflow tract and the mitral valve in pigs $^{35,36}$. Possible further deviations in the measurements might be caused by high variations in heart rate between the animals, causing the respective cardiac phases, namely best systole and best diastole, to be defined at different percentiles of the RR interval.

Due to its retrospective nature, a further flaw in this presented study was the application of the contrast. A biphasic contrast injection protocols ( $80 \%$ high flow, $20 \%$ low flow) allowing for improved contrast in the right heart, while keeping the image of the left heart structures high and diagnostic ${ }^{49,50}$ was applied for all recordings of porcine cardiac CT scans. However, as the contrast was given over either the auricular vein or the femoral vein, inhomogeneity of contrast in the right ventricle was greater in the animals with auricular vein access due to the larger amount of non-contrasted blood mixing in from the inferior vena cava. The resulting reduction in image quality of the right heart partially hampered the accurate reconstruction of the anatomy and dimensions of the tricuspid valve and the pulmonary valve respectively. 
The most common breeds of domestic swine used in biomedical research found in the literature are Yorkshire, Landrace, Duroc, Pietrain and crossbreeds such as the Swiss Large White used in this study ${ }^{51}$. Landrace, Duroc, Pietrain and crossbreeds appear to have a similar linear growth curve $\mathrm{e}^{52,53}$, while Yorkshire pigs are described to significantly differ by having a curvilinear growth pattern ${ }^{54}$. The breed difference in rate of growth of heart relative to total muscle mass has been found to be not significant in Pietrain and Large White Pigs ${ }^{53}$. Although the current study included castrated males and intact females of only Swiss Large White Pigs, potentially neglecting an influence of sex and breed, similar data in pigs of breeds with similar growth patterns might be speculated.

Last, pre-procedure planning for trans-catheter implantation studies requires thorough knowledge of cardiac dimensions to pick a suitable study animal size. However, vascular access route, including aorto-iliac vessel assessment (angulation, luminal size) and length and diameter of the abdominal aorta for delivery system length and diameter suitability is equally crucial for animal selection ${ }^{48}$. Further studies are needed to complete these missing parameters.

In conclusion, blindly correlating the body weight of a domestic swine breed, to all intra-cardiac structures leading to an accurate prediction of which pig would be the best size-matched to test a particular cardiac implant, appears unfeasible based on the acquired data. However, there are a few statements that can be made: Firstly, valvular diameters and area sizes moderately to strongly correlate with pig's body weight of this particular swine breed and possibly of swine breeds with similar growth curve patterns. The here collected data can therefore serve as a future guide in prosthetic valve size selection. Secondly, coronary ostia height and aorto-mitral angle size can be neglected in animal size selection as no change was found for either of the two parameters with increasing body weight. Lastly, length of the pulmonary artery to bifurcation as well as length of the ascending aorta can be well correlated with body weight.

Received: 9 October 2019; Accepted: 24 March 2020;

Published online: 07 April 2020

\section{References}

1. Sierra, J., Lahlaidi Sierra, N., Bednarkiewicz, M. \& Montessuit, M. [Minimal invasive cardiac surgery]. Revue medicale suisse 11, 543-545 (2015)

2. Bohula May, E. A. \& Faxon, D. Transcatheter aortic valve replacement: history and current status. Trends in cardiovascular medicine 23, 172-178, https://doi.org/10.1016/j.tcm.2012.11.001 (2013).

3. Cohn, L. H. et al. Minimally invasive cardiac valve surgery improves patient satisfaction while reducing costs of cardiac valve replacement and repair. Annals of surgery 226, 421-426; discussion 427-428 (1997).

4. Vahl, T. P., Kodali, S. K. \& Leon, M. B. Transcatheter Aortic Valve Replacement 2016: A Modern-Day "Through the Looking-Glass" Adventure. Journal of the American College of Cardiology 67, 1472-1487, https://doi.org/10.1016/j.jacc.2015.12.059 (2016).

5. Salenger, R., Gammie, J. S. \& Collins, J. A. Minimally Invasive Aortic Valve Replacement. Journal of cardiac surgery 31, 38-50, https://doi.org/10.1111/jocs.12652 (2016).

6. Koruth, J. S. et al. Pre-Clinical Investigation of a Low-Intensity Collimated Ultrasound System for Pulmonary Vein Isolation in a Porcine Model. JACC. Clinical electrophysiology 1, 306-314, https://doi.org/10.1016/j.jacep.2015.04.011 (2015).

7. Yi, G. H. et al. Safety and feasibility of percutaneous delivery of a novel circulatory assist device (CircuLite(R) SYNERGY(R)) in the swine model. EuroIntervention: journal of EuroPCR in collaboration with the Working Group on Interventional Cardiology of the European Society of Cardiology 9, 259-268, https://doi.org/10.4244/eijv9i2a42 (2013).

8. Monreal, G. et al. Large animal models for left ventricular assist device research and development. ASAIO journal (American Society for Artificial Internal Organs: 1992) 60, 2-8, https://doi.org/10.1097/mat.0000000000000005 (2014).

9. Smerup, M. et al. A long-term porcine model for evaluation of prosthetic heart valves. The heart surgery forum 7, E259-264, https:// doi.org/10.1532/hsf98.20041015 (2004).

10. Barbanti, M. et al. Anatomical and procedural features associated with aortic root rupture during balloon-expandable transcatheter aortic valve replacement. Circulation 128, 244-253, https://doi.org/10.1161/circulationaha.113.002947 (2013).

11. Ribeiro, H. B. et al. Coronary obstruction following transcatheter aortic valve implantation: a systematic review. JACC. Cardiovascular interventions 6, 452-461, https://doi.org/10.1016/j.jcin.2012.11.014 (2013)

12. Crick, S. J., Sheppard, M. N., Ho, S. Y., Gebstein, L. \& Anderson, R. H. Anatomy of the pig heart: comparisons with normal human cardiac structure. Journal of anatomy 193(Pt 1), 105-119 (1998).

13. Ma, L. et al. Double-crowned valved stents for off-pump mitral valve replacement. European journal of cardio-thoracic surgery: official journal of the European Association for Cardio-thoracic Surgery 28, 194-198; discussion 198-199, https://doi.org/10.1016/j. ejcts.2004.12.068 (2005).

14. Willson, A. B. et al. Computed tomography-based sizing recommendations for transcatheter aortic valve replacement with balloonexpandable valves: Comparison with transesophageal echocardiography and rationale for implementation in a prospective trial. Journal of cardiovascular computed tomography 6, 406-414, https://doi.org/10.1016/j.jcct.2012.10.002 (2012).

15. Santos, A. et al. Cardiovascular imaging: what have we learned from animal models? Frontiers in pharmacology 6, 227, https://doi. org/10.3389/fphar.2015.00227 (2015).

16. Sundermann, S. H. et al. Computed tomography for planning and postoperative imaging of transvenous mitral annuloplasty: first experience in an animal model. The international journal of cardiovascular imaging 31, 135-142, https://doi.org/10.1007/s10554014-0516-7 (2015).

17. Choo, S. J. et al. Development of an animal experimental model for a bileaflet mechanical heart valve prosthesis. Journal of Korean medical science 19, 37-41, https://doi.org/10.3346/jkms.2004.19.1.37 (2004).

18. Capps, S. B., Elkins, R. C. \& Fronk, D. M. Body surface area as a predictor of aortic and pulmonary valve diameter. The Journal of thoracic and cardiovascular surgery 119, 975-982, https://doi.org/10.1016/s0022-5223(00)70092-4 (2000).

19. Allan, J. S. et al. Morphometric analysis of miniature swine hearts as potential human xenografts. Xenotransplantation 8, 90-93 (2001).

20. Gutierrez, K., Dicks, N., Glanzner, W. G., Agellon, L. B. \& Bordignon, V. Efficacy of the porcine species in biomedical research. Frontiers in genetics 6, 293, https://doi.org/10.3389/fgene.2015.00293 (2015).

21. Swindle, M. M., Smith, A. C. \& Helke, K. Recommendations for Medical Device Implantation in Swine. Isr J Vet Med 68, 3-11 (2013).

22. Smith, D. et al. Classification and reporting of severity experienced by animals used in scientific procedures: FELASA/ECLAM/ ESLAV Working Group report. Lab Anim 52, 5-57, https://doi.org/10.1177/0023677217744587 (2018).

23. Worlein, J. M., Baker, K., Bloomsmith, M., Coleman, K. \& Koban, T. L. The Eighth Edition of the Guide for the Care and Use of Laboratory Animals (2011); Implications for Behavioral Management. Am J Primatol 73, 98-98 (2011). 
24. Zhang, B. L., Bianco, R. W. \& Schoen, F. J. Preclinical Assessment of Cardiac Valve Substitutes: Current Status and Considerations for Engineered Tissue Heart Valves. Frontiers in cardiovascular medicine 6, 72, https://doi.org/10.3389/fcvm.2019.00072 (2019).

25. IOo, S. (ISO).

26. Kheradvar, A., Zareian, R., Kawauchi, S., Goodwin, R. L. \& Rugonyi, S. Animal Models for Heart Valve Research and Development. Drug Discov Today Dis Models 24, 55-62, https://doi.org/10.1016/j.ddmod.2018.04.001 (2017).

27. Kirk, R. G. W. Recovering The Principles of Humane Experimental Technique: The 3Rs and the Human Essence of Animal Research. Sci Technol Human Values 43, 622-648, https://doi.org/10.1177/0162243917726579 (2018).

28. White, D. \& Wallwork, J. Xenografting: probability, possibility, or pipe dream? Lancet (London, England) 342, 879-880, https://doi. org/10.1016/0140-6736(93)91939-j (1993).

29. Niekrasz, M., Ye, Y., Rolf, L. L., Zuhdi, N. \& Cooper, D. K. The pig as organ donor for man. Transplantation proceedings 24, 625-626 (1992).

30. Douglas, W. R. Of pigs and men and research: a review of applications and analogies of the pig, sus scrofa, in human medical research. Space life sciences 3, 226-234, https://doi.org/10.1007/bf00928167 (1972).

31. Berreklouw, E. et al. Sutureless replacement of aortic valves with St Jude Medical mechanical valve prostheses and Nitinol attachment rings: feasibility in long-term (90-day) pig experiments. J Thorac Cardiovasc Surg 141, 1231-1237 e1231, https://doi.org/10.1016/j. jtcvs.2010.07.014 (2011).

32. Banai, S. et al. Transapical mitral implantation of the Tiara bioprosthesis: pre-clinical results. JACC Cardiovasc Interv 7, 154-162, https://doi.org/10.1016/j.jcin.2013.10.009 (2014).

33. Dasi, L. P. et al. On the Mechanics of Transcatheter Aortic Valve Replacement. Ann Biomed Eng 45, 310-331, https://doi.org/10.1007/ s10439-016-1759-3 (2017).

34. Cleveland, J. D. et al. Evaluation of Hemodynamic Performance of Aortic Valve Bioprostheses in a Model of Oversizing. Ann Thorac Surg 103, 1866-1876, https://doi.org/10.1016/j.athoracsur.2016.10.019 (2017).

35. Bergsland, J., Elle, O. J. \& Fosse, E. Barriers to medical device innovation. Med Devices (Auckl) 7, 205-209, https://doi.org/10.2147/ MDER.S43369 (2014)

36. Lelovas, P. P., Kostomitsopoulos, N. G. \& Xanthos, T. T. A comparative anatomic and physiologic overview of the porcine heart. Journal of the American Association for Laboratory Animal Science: JAALAS 53, 432-438 (2014).

37. George, I. et al. Aortic Valve Annular Sizing: Intraoperative Assessment Versus Preoperative Multidetector Computed Tomography. Circ Cardiovasc Imaging 10, 10.1161/CIRCIMAGING.116.005968 (2017).

38. Ribeiro, H. B. et al. Predictive factors, management, and clinical outcomes of coronary obstruction following transcatheter aortic valve implantation: insights from a large multicenter registry. Journal of the American College of Cardiology 62, 1552-1562, https:// doi.org/10.1016/j.jacc.2013.07.040 (2013).

39. Falk, V. et al. ESC/EACTS Guidelines for the management of valvular heart disease. European journal of cardio-thoracic surgery: official journal of the European Association for Cardio-thoracic Surgery 52, 616-664, https://doi.org/10.1093/ejcts/ezx324 (2017).

40. Regueiro, A., Granada, J. F., Dagenais, F. \& Rodes-Cabau, J. Transcatheter Mitral Valve Replacement: Insights From Early Clinical Experience and Future Challenges. Journal of the American College of Cardiology 69, 2175-2192, https://doi.org/10.1016/j. jacc.2017.02.045 (2017)

41. Maisano, F. et al. A translational "humanised" porcine model for transcatheter mitral valve interventions: the neo inferior vena cava approach. EuroIntervention: journal of EuroPCR in collaboration with the Working Group on Interventional Cardiology of the European Society of Cardiology 11, 92-95, https://doi.org/10.4244/eijy15m02 04 (2015).

42. van Essen, G. J. et al. Cardiovascular Function of Modern Pigs Does not Comply with Allometric Scaling Laws. Scientific reports 8 , 792, https://doi.org/10.1038/s41598-017-18775-z (2018).

43. Shields, R. G. Jr., Mahan, D. C. \& Graham, P. L. Changes in swine body composition from birth to $145 \mathrm{~kg}$. Journal of animal science 57, 43-54 (1983).

44. Swantek, P. M., Marchello, M. J., Tilton, J. E. \& Crenshaw, J. D. Prediction of fat-free mass of pigs from 50 to 130 kilograms live weight. Journal of animal science 77, 893-897 (1999).

45. Blanke, P. et al. Computed tomography imaging in the context of transcatheter aortic valve implantation (TAVI)/transcatheter aortic valve replacement (TAVR): An expert consensus document of the Society of Cardiovascular Computed Tomography. Journal of cardiovascular computed tomography 13, 1-20, https://doi.org/10.1016/j.jcct.2018.11.008 (2019).

46. DeMaria, A. N., Neumann, A., Schubart, P. J., Lee, G. \& Mason, D. T. Systematic correlation of cardiac chamber size and ventricular performance determined with echocardiography and alterations in heart rate in normal persons. The American journal of cardiology 43, 1-9 (1979).

47. Holmes, D. R. Jr. \& Mack, M. J. Transcatheter valve therapy: a professional society overview from the American College of Cardiology Foundation and the Society of Thoracic Surgeons. The Annals of thoracic surgery 92, 380-389, https://doi.org/10.1016/j. athoracsur.2011.05.067 (2011).

48. Feuchtner, G. Imaging of cardiac valves by computed tomography. Scientifica 2013, 270579, https://doi.org/10.1155/2013/270579 (2013).

49. Hinzpeter, R. et al. Computed tomography in patients with tricuspid regurgitation prior to transcatheter valve repair: dynamic analysis of the annulus with an individually tailored contrast media protocol. EuroIntervention: journal of EuroPCR in collaboration with the Working Group on Interventional Cardiology of the European Society of Cardiology 12, e1828-e1836, https://doi.org/10.4244/ eij-d-16-00891 (2017).

50. Vrachliotis, T. G. et al. Atypical chest pain: coronary, aortic, and pulmonary vasculature enhancement at biphasic single-injection 64-section CT angiography. Radiology 243, 368-376, https://doi.org/10.1148/radiol.2432060447 (2007).

51. Swindle, M. M., Makin, A., Herron, A. J., Clubb, F. J. Jr. \& Frazier, K. S. Swine as models in biomedical research and toxicology testing. Veterinary pathology 49, 344-356, https://doi.org/10.1177/0300985811402846 (2012).

52. Wetten, M., Odegard, J., Vangen, O. \& Meuwissen, T. H. Simultaneous estimation of daily weight and feed intake curves for growing pigs by random regression. Animal 6, 433-439, https://doi.org/10.1017/S1751731111001832 (2012).

53. Davies, A. S. A comparison of tissue development in Pietrain and Large White pigs from birth to $64 \mathrm{~kg}$ live weight 2 . Growth changes in muscle distribution. Animal Science 19, 377-387, https://doi.org/10.1017/S0003356100022959 (1974).

54. Quijandria, B. Jr., Woodard, J. R. \& Robison, O. W. Genetic and environmental effects on live and carcass traits at the North Carolina swine evaluation station. J Anim Sci 31, 652-655, https://doi.org/10.2527/jas1970.314652x (1970).

\section{Acknowledgements}

The authors would like to thank Flora Nicholls for helping in the preparation of the pigs for the CT scans, Robin Schneider, Dr. Hugo Battaglia, Prof. Margarete Arras and the animal caretakers of the Central Biological Laboratory for their valuable support in housing the pigs. 


\section{Author contributions}

M.L. wrote the main manuscript text. M.L. and N.C. analyzed the C.T. scans. M.L., N.C., T.F. and M.S. were involved in data acquisition and in animal care. M.E., B.K., H.A. did the C.T. scans for all animals, M.E. was involved in the C.T. analyzes. M.Y.E., S.H., V.F. and F.M. provided C.T. data from previous projects. All authors read and approved the manuscript.

\section{Competing interests}

The authors declare no competing interests.

\section{Additional information}

Correspondence and requests for materials should be addressed to M.L.

Reprints and permissions information is available at www.nature.com/reprints.

Publisher's note Springer Nature remains neutral with regard to jurisdictional claims in published maps and institutional affiliations.

(c) (i) Open Access This article is licensed under a Creative Commons Attribution 4.0 International License, which permits use, sharing, adaptation, distribution and reproduction in any medium or format, as long as you give appropriate credit to the original author(s) and the source, provide a link to the Creative Commons license, and indicate if changes were made. The images or other third party material in this article are included in the article's Creative Commons license, unless indicated otherwise in a credit line to the material. If material is not included in the article's Creative Commons license and your intended use is not permitted by statutory regulation or exceeds the permitted use, you will need to obtain permission directly from the copyright holder. To view a copy of this license, visit http://creativecommons.org/licenses/by/4.0/.

(c) The Author(s) 2020 